www.jmscr.igmpublication.org

Impact Factor 5.84

Index Copernicus Value: 83.27

ISSN (e)-2347-176x ISSN (p) 2455-0450

crossref DOI:_https://dx.doi.org/10.18535/jmscr/v5i8.36

\title{
Sandwich Technique of Repair of Primary Lumbar Hernia: A New Method
}

\author{
Dr S.T.Bhondave ${ }^{1}$, Dr Niranjan Dash ${ }^{2}$, Dr Mrs V.J. Thipse ${ }^{3}$, Dr J.M. Gadekar \\ ${ }^{1}$ Postgraduate Student, ${ }^{2,3}$ Professor, ${ }^{4}$ Professor and Head of Department
}

Department of General Surgery, DVVPF's Medical College and Hospital, Ahmednagar, Maharashtra, India

\begin{abstract}
Lumbar hernia is a rare entity. It occurs through posterolateral abdominal wall defects. It can be congenital or acquired. We report a 60 years old female patient who presented to our hospital with a right upper lumbar hernia. She underwent repair with a new sandwich technique and had a smooth postoperative course. There is no recurrence during 1 year of follow up. It is a novel idea to strengthen the defect by new technique of sandwiching two prolenemesh between layers of abdomen.
\end{abstract}

\section{Introduction}

Lumbar hernias are quite uncommon as compared to other ventral abdominal wall hernias, with fewer than 300 cases reported over the past 300 years, accounting for less than $1.5 \%$ of all abdominal hernias. ${ }^{[1,2]}$ It is the protusion of intraperitoneal or extraperitoneal contents through a defect of the posterolateral abdominal wall.

In 1672, Barbette first suggested existence of lumbar hernia. Garangeot reported the first case of lumbar hernia in 1731. Petit and Grynfeltt delineated the boundaries of the inferior and superior lumbar triangles in 1783 and 1866, respectively. 20 percent of lumbar hernias are congenital. The remaining are either primarily or secondarily acquired. ${ }^{[3]}$ The management of such patients constitutes a surgical challenge. Surgical treatment depends largely on the type and size of the hernia and both open and laparoscopic techniques can be used with good results. ${ }^{[4]}$ In our case we have encountered an old lady with primary small lumbar hernia which was managed successfully by a new sandwich technique. Sandwich technique is used to provide strength to the defect because of lack of sufficient anatomical stuctures for repair of this type of hernia.

\section{Case Report}

A 60-year-old female patient, presented to the surgical department in DVVPF's Medical college and Hospital with gradually increasing painless and reducible swelling in the right flank for the past 7 years. There was no history of trauma, previous surgery, hematuria, or altered bowel habits. Over the past 3 years, the swelling had become irreducible and painful. On admission, there was a 10x8 cm, non-tender, non-pulsatile and irreducible swelling in the right lumbar region with an expansile cough impulse (Fig.1). The examination of rest of the abdomen, left flank, back and hernia orifices was normal. Ultrasonography revealed a mass of $10 \times 10 \mathrm{~cm}$ herniating through defect measuring $1.3 \mathrm{~cm}$ noted on the posterior aspect on the right side. A 


\section{JMSCR Vol||05||Issue||08||Page 26199-26202||August}

diagnosis of an irreducible right lumbar hernia was made and patient was taken up for surgery. The patient was placed in left lateral position (Fig. 2). The swelling was explored through right flank incision. The retroperitoneal fatty globular mass suggestive of omentum was seen emerging through a narrow constricting ring through superior lumbar triangle (Fig.3). The constricting ring was released and omentectomy was done. First a prolene mesh of $7 \times 5 \mathrm{~cm}$ was placed extraperitoneally and fixed (Fig. 4). Another overlay of $7 \times 5 \mathrm{~cm}$ prolene mesh was placed over the latissimusdorsi muscle and fixed (Fig. 6). Skin and subcutaneous tissue was closed after giving negative suction drain (Fig. 7). The immediate postoperative was uneventful. Oral feeds were started on second postoperative day. Drain was removed after 4 days. The patient recoverd satisfactorily and was discharged after removal of skin sutures on $10^{\text {th }}$ postoperative day. During the follow-up visit after one month, the operative scar was found to be well healed and the patient was absolutely asymptomatic. No recurrence during last 1 year of follow up.

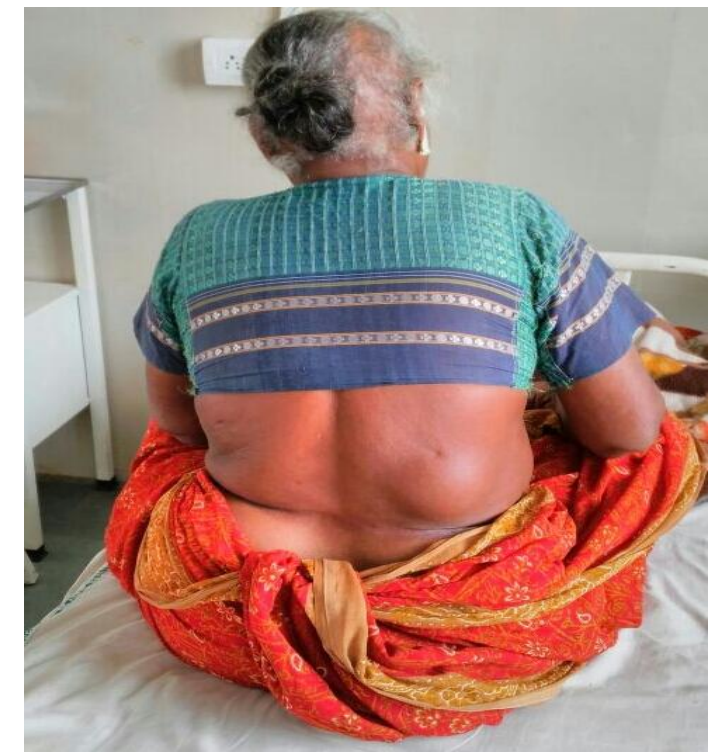

Figure 1: External appearance of lumbar hernia

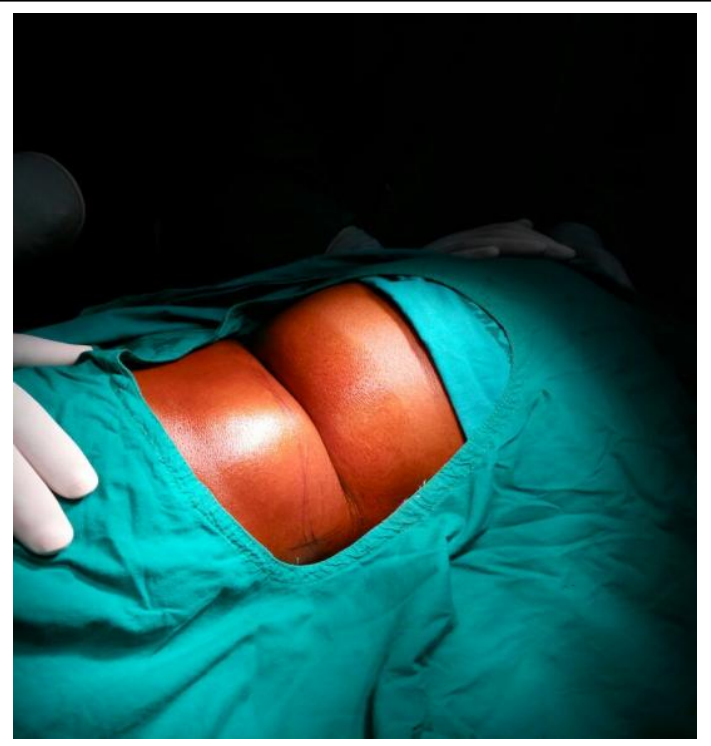

Figure 2: How it looked on OT table prior to surgery

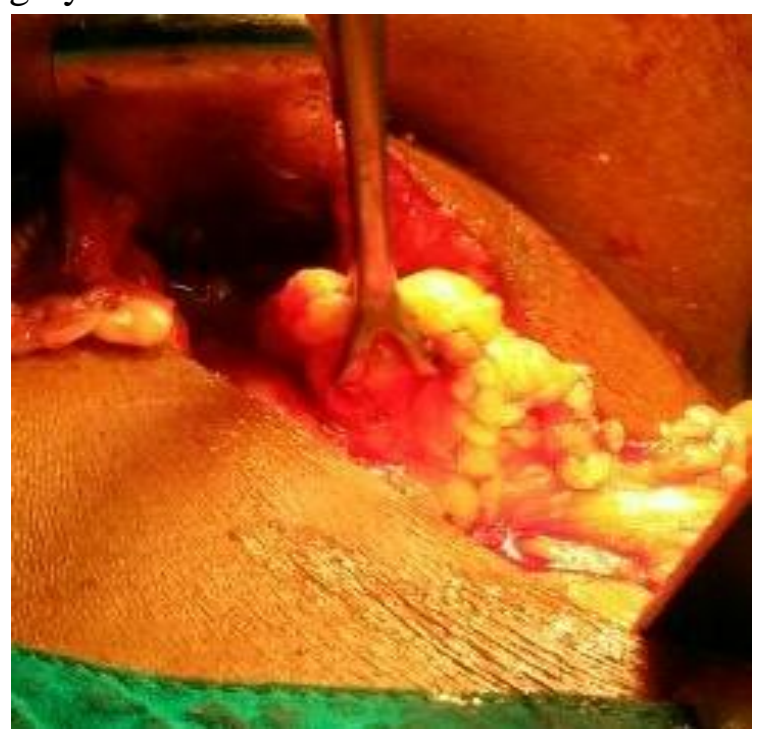

Figure 3: Protudedomental mass before excision

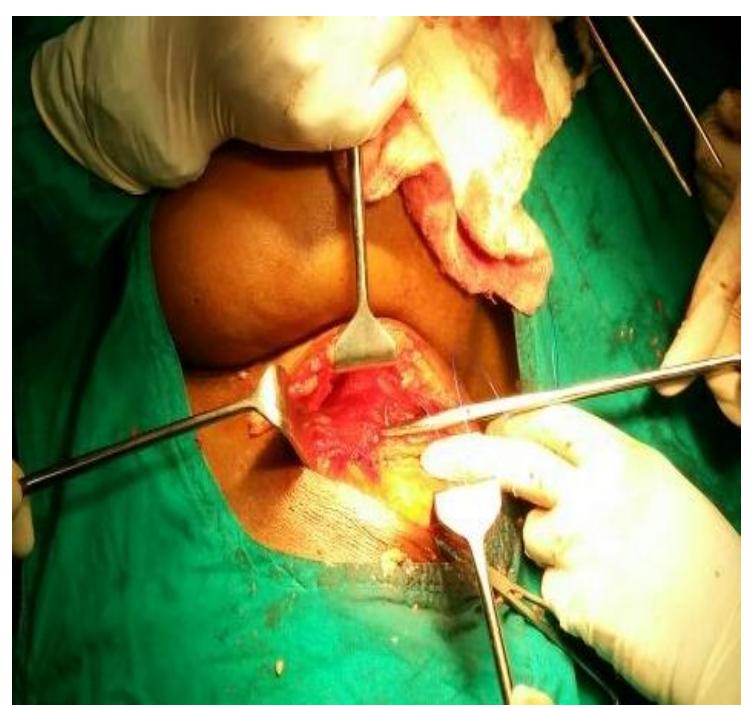

Figure 4: Repair of the defect after excision of omentum, underlay mesh fixation under progress 


\section{JMSCR Vol||05||Issue||08||Page 26199-26202||August}

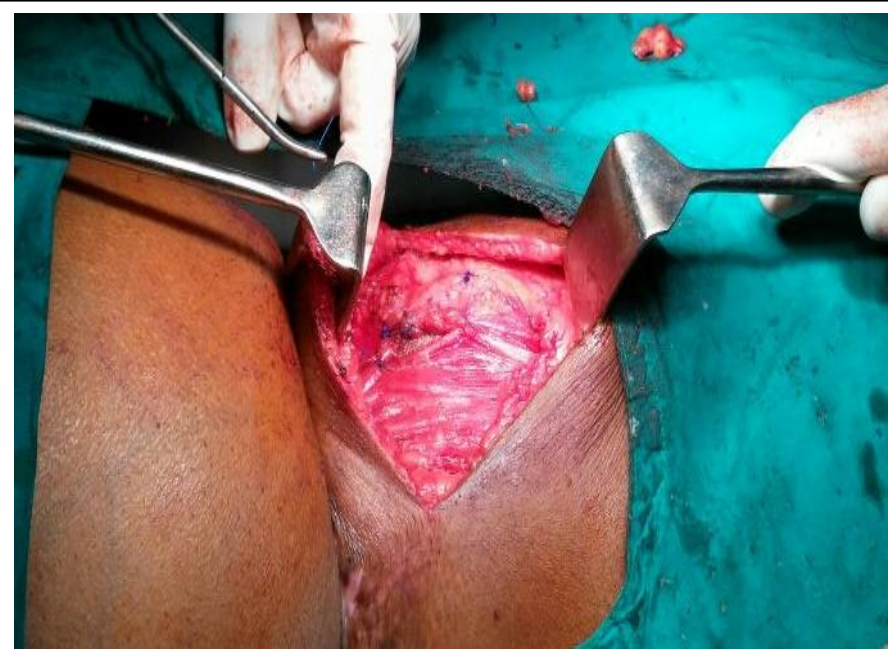

Figure 5: Apposition of latissimusdorsi muscle after underlay

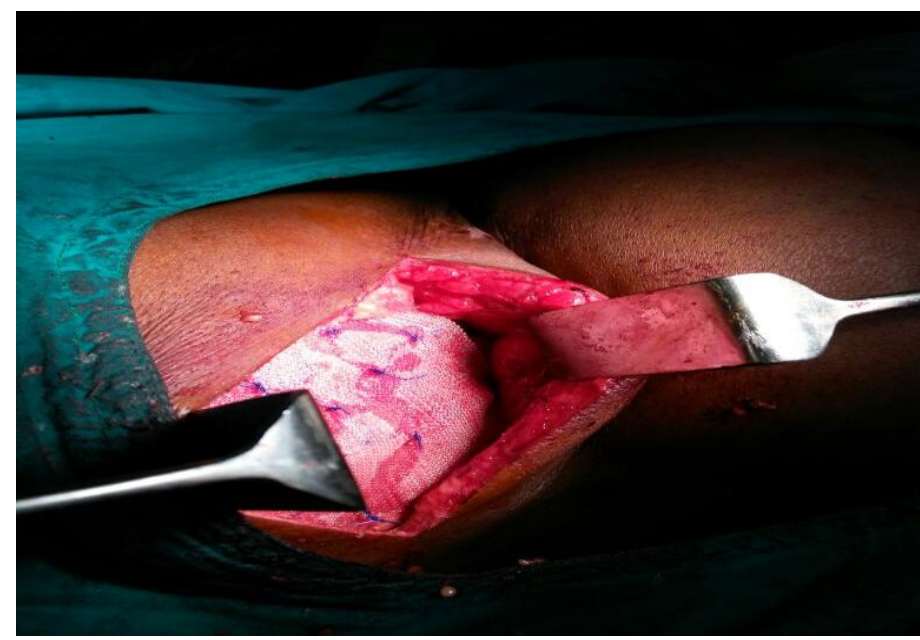

Figure 6: Overlay of mesh complete

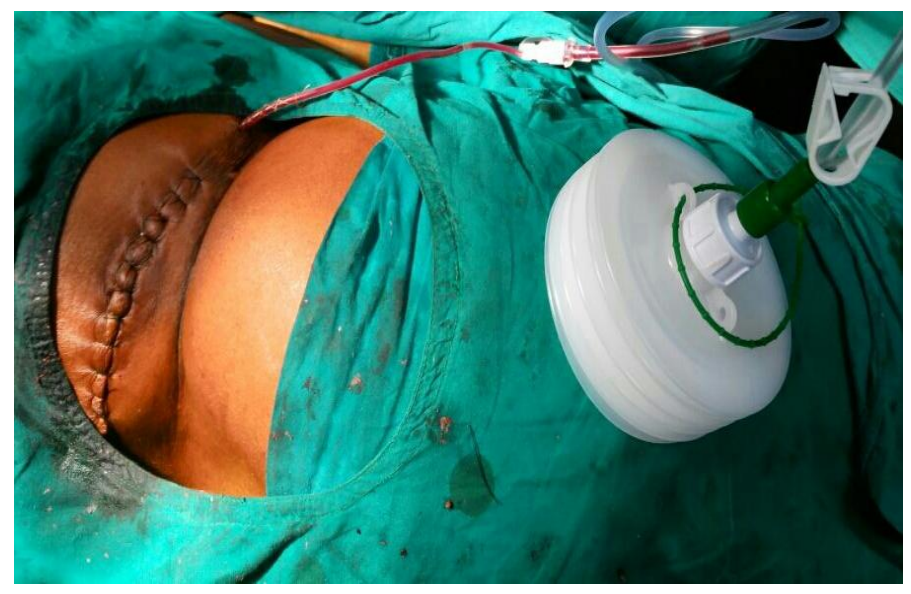

Figure 7: Skin closure with drain in situ

\section{Discussion}

Lumbar hernia are relatively rare. They occur commonly in males and are twice more common on the left than the right side. Patients are usually between 50 to 70 years old. ${ }^{[5]}$ In our case patient was 60 years old ,female and the lumbar hernia occurred on the right side which is uncommon. The lumbar region is an area defined superiorly by the $12^{\text {th }}$ rib, inferiorly by the iliac crest, medially by the erector spinae muscle group and laterally by the posterior border of the external oblique muscle as it extends from $12^{\text {th }}$ rib to iliac crest. ${ }^{[6]}$ A lumbar hernia occurs most commonly at two sites superior lumbar triangle and inferior lumbar triangle. ${ }^{[7]}$ The superior lumbar triangle is bounded superiorly by the $12^{\text {th }}$ rib, inferiorly it is bounded by the superior border of the internal oblique muscle, and posteriorly by the lateral border of the sacrospinalis muscle. The deep margin of the superior lumbar triangle is the transverses abdominis muscle and the superficial margin is the latissimusdorsi muscle. ${ }^{[8,9]}$ According to Hume, the hernia lies beneath latissimusdorsi muscle. ${ }^{[10]}$ In our case, hernia was limiting to superior lumbar triangle of Grynfeltt and pushing latissimusdorsi externally giving rise to bulge.

Surgical repair is the treatment of choice. Various surgical approaches have been described including primary repair, tissue flaps and mesh repair including laparascopic trans-abdominal and retroperitoneo-scopic approaches. ${ }^{[1]}$ In our case, right upper lumbar hernia was successfully managed by interposition of two prolene mesh. One in extraperitoneal space and the second over the latissimusdorsi, respectively. This is known as sandwich technique.

In the view of the relatively rarity of these cases, open approaches to surgery, no procedure has been shown to have a definite advantages over others. Surgical repair of lumbar hernia is difficult and challenging for surgeons. Difficulty in defining the margin of fascial defect, weakness of the involved structures and lack of surgical experience are all taken into consideration during surgical planning. For repair of lumbar hernia, very less literature is available on using sandwich technique. ${ }^{[12]}$ In our case, we have provided strength to the defect by new technique of sandwiching two prolene mesh between layers of abdomen and got good result. 


\section{Conclusion}

Repair of lumbar hernia by sandwich technique is easy and safe. It is required to strengthen the weak muscles of abdominal wall. However, it needs further study to have long term result of sandwich technique in the management of lumbar hernia.

\section{Ethical approval}

Written informed consent was obtained from the patient for publication of this case report and accompanying images. A copy of written consent is available for review by the Editor-in-Chief of this journal.

\section{References}

1. Russell RCG, Norman S, editors. Bailey \& Love's Short Practice of Surgery. $24^{\text {th }}$ edn.London : Edward Arnold 2004 ; 1287.

2. Manash Ranjan Sahoo, Anil Kumar $\mathrm{T}$. Sandwich technique of lumbar hernia: A novel technique. International Journal of Case Reports and Images, Vol. 4 No. 5, May 2013. ISSN - [0976-3198]

3. Stamatiou D1, Skandalakis JE, Shandalakis LJ, Mirilas P. Lumbar hernia: surgical anatomy, embryology, and technique of repair.Am Surg. 2009 Mar; 75(3): 202-7.

4. Giuseppe PietroMingolla and Gianfranco Amelio.Lmbar hernia misdiagnosed as a subcutaneous lipoma: a case report. Journal of medical case reports 2009, 3: 9322.

5. Geis WP, Hodakowski GT. Lumbar hernia. In: Nyhus L, Condon R, editors. Hernia. $5^{\text {th }}$ ed. Philadelphia 2001; 425-7.

6. Swartz W.T. Lumbar hernia. In: NyhusL.M.,Condon R.E., editors.Hernia. $2^{\text {nd }} \quad$ ed. Lippincott; Philadelphia: 1978.pp.409-426.
7. Petit J.L. vol.2.Paris, TF Didot; 1774. Pp. 256-258. (Traite des maladies chirurgicales, et des operations qui leurconviennent).

8. Grynfeltt J. Quelques mots sur la hernielombaire. Montpellier Medical. 1886; 16:323.

9. Lesshaft P. Lumbalgegren in anatomischChirurgischer, Himsicht. Archives of Anatomy and Physiology Wissensch Medicine.1870;264.

10. Hume G.H. Case of strangulated lumbar hernia. British Medical Journal.1889;2:73.

11. Carbonell AM, Kercher KW, SigmonL,et al. A novel technique of lumbar hernia repair using bone anchor fixation. Hernia 2005;9(1): 22-5.

12. Bleichrodt RP, Maylor AW, de VriesReilingh TS, Buyne O, Bonenkamp JJ, van Goor $\mathrm{H}$, The omentumpolypropelene sandwich technique: an attractive method to repair large abdominal- wall defects in the presence of contamination or infection. Hernia 2007 Feb;11(1):71-4. 